\title{
Antifeedant Activity Evaluation of Withanolides from Jaborosa integrifolia
}

\author{
Clarisa E. Vaccarini and Gloria M. Bonetto \\ Departamento de Química Orgánica, Facultad de Ciencias Químicas - UNC. Ciudad Universitaria. \\ 5000 Córdoba, Argentina \\ E-mail: gloriamb@dqo.fcq.unc.edu.ar
}

\begin{abstract}
Antifeedant activity of the 4-deoxi-27-hydroxi-withanolides (1, 2 y 3) isolated from Jaborosa integrifolia (Solanaceae) was investigated in caterpillar Spodoptera littoralis on Leaf Disk Choice Bioassay. Results indicate that the best feed inhibition effect is due to Jaborosalactone A.
\end{abstract}

\section{Introduction}

Jaborosa integrifolia (Solanaceae) is native from Argentina. Our phytochemical studies on this species confirm the occurrence of withanolides in roots. The compounds named Jaborosalactones A (1), B (2) and D (3) were isolated in previous studies of this species and from Vassobia breviflora (SENDTN.) HunZ. (Sub. nom.: Acnistus brevilorus GRISEB.) [1-4].

In an interdisciplinary project for bioactive compounds research from natural sources we determined biological properties of the tree withanolides (1, 2 and 3) isolated from J. integrifolia. These compounds were evaluated as antifeedant on leaf choice disk test with fresh leaf of Zea mais and $\mathrm{Cu}$ curbita peppo.

From the consumed area dates is calculated the antifeedant index as (1 - T/C) $\mathbf{x} 100$, where $\mathbf{T}$ and $\mathbf{C}$ are, the consumed area of treated and control disks respectively [5].

\section{Experimental}

The dried and powered roots of J. integrifolia were extracted with ethanol at room temperature and concentrated at reduced pressure. The residue was taken with hexane-methanol-water and so deffated. The methanolic layer was concentrates in vacuo, the methanol was eliminated and the water was extracted with chloroform. The chloroformic layer was concentrated in vacuo and the extract was processed by chromatography yielding three withanolides Jaborosalactone A (1), Jaborosalactone B (2) and Jaborosalactone D (3). Bioassays with S. littoralis were made according standard procedure. 


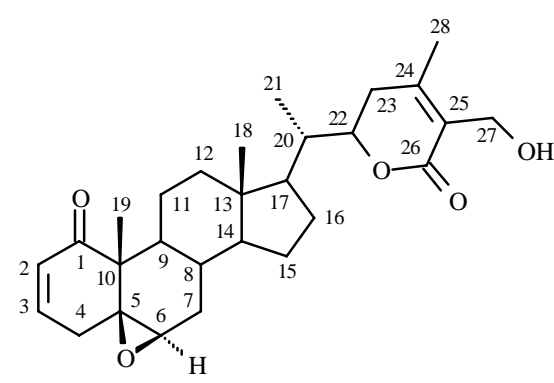

(1) Jaborosalactone A

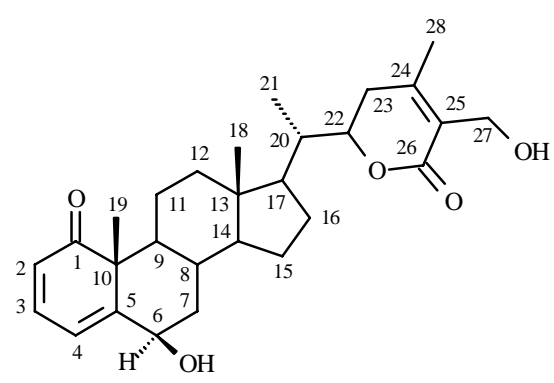

(2) Jaborosalactone B

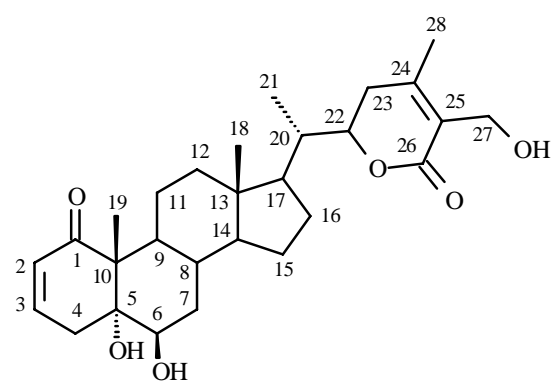

(3) Jaborosalactone D

\section{Results and discussion}

Results indicate that the compound $\mathbf{1}$ show a potent feeding inhibitory effect for the caterpillars. We observe a $74 \%$ of feeding inhibition $(\mathrm{p}=0,05)$ in the disk treated with $20 \mu \mathrm{g}-\mathrm{cm}^{2}$. The dates for compounds 2 and 3 indicate that these compounds has not significant effect $(+19 \%$ and $-19 \%, p=0.05$, respectively) on the alimentation of the caterpillars. We conclude that exist correlation between the marked difference on the antifeedant effect and the differential structural arrangement in A and $\mathrm{B}$ rings of the withanolides tested.

\section{References and Notes}

1. Bukovits, G. J.; Gros, E. G. Phytochemistry 1979, 18, 1237-1239.

2. Tchesche, R.; Schwang, H.; Legler G. Tetrahedron 1966a, 22, 1121-1127.

3. Tchesche, R.; Schwang, H.; Fehlhaber, W.; Snatzke, G. Tetrahedron 1966b, 22, 1129.

4. Tchesche, R.; Baumgarth, M.; Welzel, P. Tetrahedron 1968, 24, 5169-5179.

5. Hassanali, A.; Lwande, W. Antipest Secondary Metabolites from African Plants, pag. 78-94 en INSECTICIDES OF PLANTS ORIGIN. ACS symp.Ser. 387, 1989. 